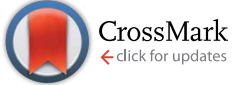

Cite this: RSC Adv., 2016, 6, 56986

Received 30th March 2016

Accepted 30th May 2016

DOI: 10.1039/c6ra08228a

www.rsc.org/advances

\title{
Conductivity of composite membrane-based poly(ether-ether-ketone) sulfonated (SPEEK) nanofiber mats of varying thickness $\dagger$
}

\author{
J. L. Reyes-Rodriguez, ${ }^{a}$ O. Solorza-Feria, ${ }^{a}$ A. García-Bernabé, ${ }^{b}$ E. Giménez, ${ }^{c}$ \\ O. Sahuquilloc and V. Compañ ${ }^{\star b}$
}

\begin{abstract}
Nanofiber mats of SPEEK ${ }_{70 w t \%}-\mathrm{PVB}_{30}$ wt\% (polyvinyl butyral)-based composite membranes were prepared by varying the electrospinning time in order to obtain mats with different thicknesses. These mats were embedded in SPEEK 65 wt\% - PVA $_{35 w t \%}$ (polyvinyl alcohol) polymer solution to fill the pores in the fibers. The obtained membranes with different mat thicknesses have been characterized by water uptake, ionic exchange capacity, scanning electron microscopy, mechanical properties and proton conductivity. Microtensile test studies reveal that the maximum tensile strength increases as the thickness of the SPEEK-PVB nanofiber mats increases, resulting in more flexible composite membranes compared to a pure SPEEK-PVA membrane obtained by casting. The proton conductivity occurs more easily through the nanofiber than through the matrix phase, and the best conductivity $\left(0.038 \mathrm{~S} \mathrm{~cm}^{-1}\right)$ was measured at $120{ }^{\circ} \mathrm{C}$ for the composite membrane of SPEEK-PVB nanofiber mats obtained after 12 hours of electrospinning time. This value suggests that our composite membranes have high potential to function in the temperature range between 100 and $140{ }^{\circ} \mathrm{C}$ without losing their strength and while maintaining their high proton conductivity, making them an excellent candidate for fuel cells that operate at intermediate temperatures.
\end{abstract}

\section{Introduction}

Proton exchange membrane fuel cells (PEMFCs) are promising electrochemical energy conversion devices for transportation and stationary applications due to their high efficiency, high power density and low emission. ${ }^{\mathbf{1} 2}$ The heart of a PEMFC is the polymer electrolyte membrane. Currently, perfluorosulfonic acid membranes with a hydrophobic backbone and hydrophilic sulfonic acid pendant side chain, such as Nafion ${ }^{\circledR}$, have been widely used as PEMs in fuel cells fed by hydrogen, and also with methanol in direct methanol fuel cells (DMFCs); this is because this polymer is considered to be the best-functioning proton conductor at low temperature due to its combination of good chemical and mechanical stability with relatively high conductivity.,

${ }^{a}$ Departamento de Química - Centro de Investigación y de Estudios Avanzados del I.P.N., Av. IPN 2508, Col. San Pedro Zacatenco, 07360 México D.F., Mexico

${ }^{b}$ Escuela Técnica Superior de Ingenieros Industriales - Departamento de Termodinámica Aplicada, Universidad Politécnica de Valencia, Camino de vera $s / n$, 46020 Valencia, Spain. E-mail: vicommo@ter.upv.es; Fax: +34 9638779 24; Tel: +34963879328

${ }^{c}$ Escuela Técnica Superior de Ingenieros Industriales - Departamento de Ingeniería Mecánica y de Materiales, Universidad Politécnica de Valencia, Camino de vera $s / n$, 46020 Valencia, Spain

$\dagger$ Electronic supplementary information (ESI) available. See DOI: 10.1039/c6ra08228a
However, efficient use of Nafion membranes is limited to a low temperature range below their glass transition temperature $\left(T_{\mathrm{g}}\right)$, in the vicinity of $100{ }^{\circ} \mathrm{C}$, because their performance decreases considerably as a result of low proton conductivity due to dehydration at higher temperatures; this limits the maximum operating temperature of Nafion membranes to $80{ }^{\circ} \mathrm{C} .{ }^{5,6}$ In contrast, the advantages of operating PEMFCs at high temperatures $\left(100\right.$ to $\left.200{ }^{\circ} \mathrm{C}\right)$ include several factors, such as: (1) increased tolerance to $\mathrm{CO}_{2}$ poisoning of Pt-based noble catalysts by using hydrogen from the reforming process and/or air as the oxygen source, (2) avoidance of the necessity of cooling systems and potential use of thermal energy for a cogeneration process, (3) avoidance of the use of humidification systems in the gas supply to maintain hydration, (4) increased diffusion rate of the charge carriers of the membrane, (5) accelerated kinetic reaction of the catalytic materials with the reaction gases. ${ }^{5-12}$ For these reasons, high temperature fuel cells (HT-PEMFC) are considered to be a potential solution to address the current technical challenges of low temperature fuel cells (LT-PEMFC) and may be an ideal alternative, at least, for automotive purposes..$^{\mathbf{5}, 9}$

Significant efforts have been made to search for new polymeric materials with proton exchange capacity, such as modified perfluorosulfonic acid polymer membranes, alternative sulfonated polymers, composite membranes, and acid-base polymer membranes. ${ }^{\mathbf{8 , 1 3 - 1 8}}$ For more details and information, we 
recommend the work of Bose et al., ${ }^{6}$ where current trends and challenges in new polymer membranes are addressed. Among these, one of the most studied systems for HT-PEMFC applications is $\mathrm{H}_{3} \mathrm{PO}_{4}$ doped polybenzimidazol (PBI), reported by Savinell and co-workers. ${ }^{19-23}$ Proton conduction through the solid PBI matrix is less dependent on water content than that of the perfluorosulfonic system, ${ }^{\mathbf{1 6 , 1 9 , 2 3}}$ which allows these membranes to be operated at 100 to $200{ }^{\circ} \mathrm{C}$ with low relative humidity. However, the disadvantage of using acid doped PBI membranes is that the typical Pt based catalyst materials tend to suffer agglomeration and dissolution under high temperature and in the acidity of the $\mathrm{H}_{3} \mathrm{PO}_{4}$ environment. ${ }^{17,23}$

Our research group has been focusing on SPEEK polymer, ${ }^{24-26}$ which has been extensively studied by numerous research groups due to its high thermal $\left(T_{\mathrm{g}}>170{ }^{\circ} \mathrm{C}\right)$ and chemical stabilities, availability of materials and low cost for application as a precursor of protonic exchange membranes for intermediate temperature (100 to $\left.150{ }^{\circ} \mathrm{C}\right)$ PEMFCs and DMFCs. ${ }^{5,6,27-33}$ The main drawback of SPEEK has been found to be excessive swelling and dissolution in hot water, which prevents its practical use in DMFCs at intermediate temperatures $^{\mathbf{2 4 , 2 6}}$ but not in the case of PEMFCs fed with hydrogen. Crosslinking SPEEK with other polymers enhances its mechanical stability under high temperature conditions. ${ }^{\mathbf{2 6 , 2 8 , 3 0 , 3 2}}$ Immersion of the membranes in boiling water for $1 \mathrm{~h}$ is the selected examination procedure. ${ }^{24}$

In our previous work, we observed that the nanofiber morphology exhibits a large surface area which can be functionalized and modified to tailor the interface properties; nanocomposite membranes were prepared based on (i) a Nafion ${ }^{\circledR}$ matrix with poly-vinyl alcohol (PVA) nanofibers (Nafion/PVA) and (ii) a blend based on poly-ether-ether-ketone sulfonated with PVA (SPEEK-PVA) with nanofibers of SPEEK blended with polyvinyl butyral (SPEEK-PVB) to obtain the composite membrane (SPEEK-PVA/SPEEK-PVB). The former is intended for DMFC applications below $80{ }^{\circ} \mathrm{C}$ and the latter for operation within the 80 to $140{ }^{\circ} \mathrm{C}$ range. From the characterization of the obtained nanocomposite membranes, it is revealed that the nanofibers of SPEEK/PVB have higher proton conductivity than those prepared by the casting method. The incorporation of the nanofiber mats into the SPEEK-PVA matrix provided mechanical stability and some proton conductivity up to a crosslinking temperature of $120{ }^{\circ} \mathrm{C} .{ }^{24,25}$ As a result, mechanical reinforcement of the composite membranes leads to lower water uptake and swelling values, which causes the methanol permeability to decrease in DMFC conditions. ${ }^{24-26}$ In these studies, the surface of the PVA nanofibers was functionalized with sulfonic acid moieties through the reactivity of the $\mathrm{OH}$ groups of PVA via an acetal formation reaction. The interface compatibility was attributed to hydrogen bonding between the sulfonic acid species $\left(-\mathrm{SO}_{3} \mathrm{H}\right)$. The PVA nanofiber mats also provided a strong mechanical reinforcing effect to the composite membranes, which resulted in the successful preparation of low thickness membranes $(<20 \mu \mathrm{m})$. Additionally, low thickness membranes with reduced ohmic losses can be fabricated. ${ }^{34}$ Generally, thin membranes are preferred for the operation of hydrogen fuel cells at lower relative humidity levels because they facilitate water transport between the cathode and the anode.

Electrospinning is a suitable and standard technique for the production of nanofibers made from a broad selection of materials, although new, more productive methods are being developed. ${ }^{34-43}$ In this sense, electrospun nanofibers are receiving considerable attention in the fabrication of novel proton exchange membranes with enhanced mechanical, chemical and proton conductivities ${ }^{36-41}$ where the conduction mechanism can occur more efficiently through the surface of the nanofibers. ${ }^{43}$

From the experience collected from our previous studies, in this work we offer a new strategy to obtain composite membranes for use in fuel cells operating in the range of 120 to $140{ }^{\circ} \mathrm{C}$. In order to attain this goal, we follow our previous strategy of preparing composite membranes of hydrophilic PVA and hydrophobic PVB blended with SPEEK with different nanofiber thicknesses obtained by varying the electrospinning time. The corresponding membranes were crosslinked and characterized by water uptake, ionic exchange capacity, scanning electron microscopy (SEM), mechanical properties and proton conductivity, in order to probe which composition of nanofiber mat and polymer matrix was the best combination to build membrane-electrode assemblies. ${ }^{24-26}$

\section{Experimental section}

\subsection{Materials}

Poly ether ether ketone (VICTREX® PEEK 450 PF) was acquired from Victrex Inc. in the form of a powder $(50 \mu \mathrm{m})$ with a molecular weight $M_{\mathrm{w}}$ of 39200 and a density of $1.30 \mathrm{~g} \mathrm{~cm}^{-3}$. PEEK was dried at $150{ }^{\circ} \mathrm{C}$ for $3 \mathrm{~h}$ in an oven, as specified in its technical data sheet. Polyvinyl butyral (PVB) Butvar® B-98 powder was purchased from Sigma-Aldrich. Granulated polyvinyl alcohol (PVA) Mowiol® 28-99 grade was donated by Kuraray Europe GmbH Company (Frankfurt, Germany). Concentrated sulphuric acid $\left(\mathrm{H}_{2} \mathrm{SO}_{4}\right)$ with a specified concentration of 95 to $98 \mathrm{wt} \%$ was purchased from Scharlau. $N, N$ Dimethylacetamide (DMAc) 99.8\% solvent was purchased from Sigma-Aldrich. PVB, PVA, sulfuric acid and DMAc were used as received.

\subsection{Sulfonation of PEEK}

The polymeric material chosen for the membrane preparation was poly ether ether ketone (PEEK), which requires a sulfonation process to incorporate sulfonic acid groups that will enable the transport of protons through ion channels in the structure of the final membrane. In a typical process, $30 \mathrm{~g}$ of dry PEEK powder is gradually dissolved in concentrated sulfuric acid at 55 ${ }^{\circ} \mathrm{C}$ under continuous mechanical stirring, maintaining a concentration ratio of 5/95 (w/v) PEEK/sulfuric acid. ${ }^{29-31}$ During the slow addition of the PEEK powder, the color of the mixture changes to an intense yellow-red. After the complete dissolution of PEEK ( $\sim 45 \mathrm{~min})$, the polymer solution is maintained under the same conditions of temperature and stirring for 12 hours. Then, the polymer solution is precipitated (using 
a syringe) in cold deionized water under mechanical stirring to obtain thin white threads of the sulfonated poly ether ether ketone (SPEEK) modified polymer. The threads are successively immersed in deionized water to remove residual sulfuric acid until the $\mathrm{pH}$ value of the filtered wash water is near neutrality. The threads are dried at $80^{\circ} \mathrm{C}$ in an oven overnight to remove as much water as possible. In this step, the threads merge into a yellow solid mass that is similar to a gelatin. This gelatin is cut into small pieces that are dried at $100{ }^{\circ} \mathrm{C}$ until constant weight is observed. The final dark red product is stored in a sealed container to avoid absorption of water.

The sulfonation reaction is an electrophilic substitution that occurs at certain active sites of the PEEK structure where the electron density favors substitution. The electrophilic substitution can take place in one of the four available positions of the aromatic ring flanked by ether groups of the monomer unit (first type substitution). It is not possible to carry out a sulfonation process under normal conditions on the aromatic rings linked by the carboxylic group due to its electron withdrawing nature, which reduces the electron density on those sites. However, by increasing the temperature and extending the reaction times, it is possible to perform substitutions in the other two aromatic rings (second type substitution). ${ }^{5,29}$ The reaction was carried out at $55{ }^{\circ} \mathrm{C}$ for 12 hours of continuous sulfonation to prepare SPEEK with a high degree of sulfonation, taking into consideration our laboratory conditions.

\subsection{Preparation of membranes}

2.3.1 Electrospinning of $\mathrm{SPEEK}_{70}-\mathrm{PVB}_{30}$ nanofiber mats. The fabrication of nanofiber mats using the electrospinning method has attracted considerable attention from researchers, mainly due to the versatility and scaling potential offered by this technique, which produces nanofiber structures with porosity, orientation and dimension control. In general, the technique involves pumping a polymer solution into a capillary that holds an electrostatic attraction induced by a collector with a high applied electric field. Although the process seems simple and straightforward, there are some variables that influence the morphology and the structural and mechanical properties of the fibers, such as the viscosity and concentration of the polymer solution, the solvent used and its vapor pressure, the capillary-collector distance, the applied voltage, the type of collector (plate or rotating drum), the flow rate, and the environmental conditions of humidity and temperature. ${ }^{\mathbf{2 4 , 4 4}}$ All these factors complicate the optimization of electrospinning parameters, especially as environmental factors.

According to previous reports of our research group, ${ }^{25,26}$ a blended solution of SPEEK and PVB was prepared in DMAc solvent maintaining a ratio of $70 / 30 \mathrm{w} / \mathrm{w}$, respectively, as follows: $14 \mathrm{~g}$ of dry SPEEK and $6 \mathrm{~g}$ of PVB were dissolved in DMAc at $80^{\circ} \mathrm{C}$ under magnetic stirring until complete homogenization $(\sim 1 \mathrm{~h})$. A calculated volume of DMAc was added to obtain a concentration of $20 \mathrm{wt} \%$ of the total polymer mass (SPEEK-PVB) with respect to the solvent mass. A concentration lower than $17.5 \mathrm{wt} \%$ leads to a low solution viscosity and causes defects, known as beads, in the fiber structure. Therefore, the optimum working range is between 17.5 and $20 \mathrm{wt} \%$. Due to the environmental conditions of humidity and temperature in our laboratory, the SPEEK-PVB solution was always maintained under magnetic stirring before being electrospun. Even the syringe was replaced with fresh polymer solution after a certain amount of time to prevent phase separation of the components. Fiber mats of 20 wt\% SPEEK $_{70}-\mathrm{PVB}_{30} / \mathrm{DMAc}$ solution were electrospun using a Super ES-2 model E-Spin Nanotech electrospinning machine. The polymer solution was injected by a syringe pump with a flow rate of $0.2 \mathrm{ml} \mathrm{h}^{-1}$ to the tip of a steel capillary which was separated by $18 \mathrm{~cm}$ from the rotating drum collector $(1200 \mathrm{rpm})$. A potential difference of $20 \mathrm{kV}$ was applied between both electrodes. The electrospinning time was varied from 2 to 14 hours (every $2 \mathrm{~h}$ ) with the purpose of obtaining different mat thicknesses. The obtained nanofiber mats were dried in an oven first at $80{ }^{\circ} \mathrm{C}$ for $3 \mathrm{~h}$ and then at $160{ }^{\circ} \mathrm{C}$ for 30 minutes in order to remove residual DMAc solvent. The mats showed hydrophobic behavior in the presence of water droplets but were practically soluble when immersed in a mixture of ethanol and water. Cross-linking at $180{ }^{\circ} \mathrm{C}$ for $2 \mathrm{~h}$ resolved this problem, providing high chemical stability to the fibers, a property that is remarkable for applications in methanol or ethanol fuel cells. In this step, a color change from white to brown was observed.

2.3.2 SPEEK-PVB-PVA composite membranes. A $12 \mathrm{wt} \%$ SPEEK $_{65}-\mathrm{PVA}_{35} / \mathrm{H}_{2} \mathrm{O}$ polymer solution was prepared as follows: $15.6 \mathrm{~g}$ of dry SPEEK and $8.4 \mathrm{~g}$ of PVA were dissolved in deionized water at $80{ }^{\circ} \mathrm{C}$ under magnetic stirring until complete homogenization $(\sim 1 \mathrm{~h})$. Thereafter, the solution was cooled to room temperature. Each SPEEK-PVB square mat was firstly moistened with deionized water on a filter paper, in order to extend it, and then was transferred as a decal between two firmly fixed Teflon cloth frames. The yellow SPEEK-PVA polymer solution $(\sim 1.5 \mathrm{ml})$ was spread with a soft bristle brush along the mat, and then each mat was dried in an oven at $60{ }^{\circ} \mathrm{C}$ for 15 minutes to evaporate water. The same process was repeated for the reverse face of the mat. Finally, the dry impregnated mats were cut along the Teflon frame boundary and then were cross-linked in a hot plate press at $180{ }^{\circ} \mathrm{C}$ for 10 minutes (using Teflon cloth pieces as protectors) to obtain SPEEK-PVB-PVA composite membranes. In this step, a color change from brown to dark was observed (see Fig. S1 in the ESI $\dagger$ ). It is important that the heating temperature for the cross-linking does not exceed $200{ }^{\circ} \mathrm{C}$ to prevent the desulfonation of SPEEK by $-\mathrm{SO}_{3}$ release, as reported in the literature. ${ }^{28}$ Thus, seven composite membranes were obtained and identified as $\mathrm{M}$ $x$, where $x$ is the number of hours of electrospinning time used to obtain the SPEEK-PVB nanofiber mats with different thicknesses (Table 1) embedded later in SPEEK-PVA polymer solution.

For comparison, a pure SPEEK-PVA membrane was prepared by casting following the same methodology described above using the $12 \mathrm{wt} \% \mathrm{SPEEK}_{65}-\mathrm{PVA}_{35} / \mathrm{H}_{2} \mathrm{O}$ polymer solution and the Teflon frames as the cast.

\subsection{Characterization of the nanofibers and composite membranes}

2.4.1 Scanning electron microscopy (SEM) analysis. The morphology of the $12 \mathrm{~h} \mathrm{SPEEK}{ }_{70}-\mathrm{PVB}_{30}$ nanofiber mat and the 
Table 1 Thicknesses of nanofiber mats and composite membranes as a function of electrospinning time

\begin{tabular}{|c|c|c|c|c|c|c|c|}
\hline Membrane & M-02 & M-04 & M-06 & M-08 & M-10 & M-12 & M-14 \\
\hline Electrospinning time $(\mathrm{h})$ & 2 & 4 & 6 & 8 & 10 & 12 & 14 \\
\hline $\begin{array}{l}\operatorname{SPEEK}_{70}-\mathrm{PVB}_{30} \text { nanofiber mat thickness } \\
(\mu \mathrm{m})\end{array}$ & 9 & 15 & 29 & 47 & 62 & 114 & 140 \\
\hline
\end{tabular}

structures of the SPEEK-PVB-PVA composite membranes were investigated using a field emission scanning electron microscope (FESEM model Ultra 55, Zeiss). Cross-sectional observations were made for SPEEK-PVB-PVA composite membranes which were previously frozen in liquid nitrogen and were then fractured. All the samples were coated with platinum sputtering before SEM observations.

2.4.2 Water uptake, swelling, ion exchange capacity and sulfonation degree. Square samples $(2 \times 2 \mathrm{~cm})$ of SPEEK-PVBPVA composite membranes were immersed in boiling deionized water for $1 \mathrm{~h}$. Then, excess water was dried with filter paper. The water uptake value was calculated from the average of three similar composite membranes of each type, considering the difference between the weight of the wet membranes $\left(W_{\text {wet }}\right)$ and the dry weight (dried in oven for 3 hours at $100{ }^{\circ} \mathrm{C}, W_{\text {dry }}$ ) according to eqn (1):

$$
\text { Water uptake }(\%)=\frac{W_{\text {wet }}-W_{\text {dry }}}{W_{\text {wet }}} \times 100
$$

The swelling degrees, both in-surface and in-thickness, were calculated by similar expressions considering the wet surface area $(A)$ and/or wet thickness $(L)$ (under the same hydration conditions mentioned above) of the composite membrane samples with respect to the dry conditions, according to eqn (2) and (3):

$$
\begin{gathered}
\text { Surface swelling }(\%)=\frac{A_{\mathrm{wet}}-A_{\mathrm{dry}}}{A_{\mathrm{wet}}} \times 100 \\
\text { Thickness swelling }(\%)=\frac{L_{\mathrm{wet}}-L_{\mathrm{dry}}}{L_{\mathrm{wet}}} \times 100
\end{gathered}
$$

The ion exchange capacity (IEC) was estimated from samples ( $\sim 100$ to $200 \mathrm{mg}$ ) of the pristine SPEEK polymer, $12 \mathrm{~h} \mathrm{SPEEK}_{70^{-}}$ $\mathrm{PVB}_{30}$ nanofiber mat and SPEEK-PVB-PVA composite membranes which were immersed in $50 \mathrm{ml}$ of $1 \mathrm{M} \mathrm{NaCl}$ solution and stored in sealed bags for 3 days. During this time, the protons liberated from the SPEEK polymer chains interacted with the $\mathrm{Cl}^{-}$anions of the salt to form $\mathrm{HCl}$ by an ionic exchange mechanism. The solution was filtered and then titrated in triplicate with a $0.0095 \mathrm{M} \mathrm{NaOH}$ standard solution. The IEC $\left(\right.$ meq $\mathrm{g}^{-1}$ ) was calculated according to eqn (4):

$$
\mathrm{IEC}=\frac{V_{\mathrm{NaOH}} \times C_{\mathrm{NaOH}}}{m}
$$

where $V_{\mathrm{NaOH}}$ and $C_{\mathrm{NaOH}}$ were the volume $(\mathrm{mL})$ and the concentration $\left(\mathrm{mol} \mathrm{L}^{-1}\right)$ of the $\mathrm{NaOH}$ solution, respectively, and $m$ was the weight (g) of each dry sample in protonic form. The sulfonation degree (SD) was determined by eqn (5) according to a previous report: ${ }^{5,29}$

$$
\mathrm{DS}(\%)=\frac{M_{\mathrm{SPEEK}}}{\frac{1000}{\mathrm{IEC}}-M_{-\mathrm{SO}_{3} \mathrm{H}}} \times 100
$$

where $M_{\text {SPEEK }}$ and $M_{-\mathrm{SO}_{3} \mathrm{H}}$ were the molecular weights of the SPEEK monomer repeat unit (288) and sulfonic group $-\mathrm{SO}_{3} \mathrm{H}$ (81), respectively.

The SPEEK-PVB nanofiber mat sample with $12 \mathrm{~h}$ of electrospinning time was chosen for physical characterization because, as will be seen later, it had higher proton conductivity when embedded in the final membrane and therefore is of greater interest.

2.4.3 Mechanical properties. The mechanical properties of the $12 \mathrm{~h}$ SPEEK $_{70}-\mathrm{PVB}_{30}$ nanofiber mat, the SPEEK-PVB-PVA composite membranes and the pure $\mathrm{SPEEK}_{65}-\mathrm{PVA}_{35}$ membrane were measured using a DEBEN microtest tensile module instrument calibrated at $150 \mathrm{~N}$. Five samples of around $7 \times 20$ $\mathrm{mm}$ of each membrane were clamped on the tensile module with a separation of $10 \mathrm{~mm}$, considering the electrospinning orientation of the fiber mats to avoid their fracture. The speed rate was fixed at $0.4 \mathrm{~mm} \mathrm{~min}^{-1}$. The Young's modulus, the maximum tensile strength, the maximum strain and the tenacity were obtained from the tensile stress $v s$. strain plots.

2.4.4 Electrochemical impedance spectroscopy (EIS). The proton conductivity of the SPEEK-PVB-PVA composite membranes in the transversal direction were measured in the temperature range between 20 and $140{ }^{\circ} \mathrm{C}$ by impedance spectroscopy in the frequency interval of $10^{-1}<f<10^{7} \mathrm{~Hz}$, applying a $0.1 \mathrm{~V}$ signal amplitude. A Novocontrol broadband dielectric spectrometer (Hundsangen, Germany) integrated with an SR 830 lock-in amplifier with an Alpha dielectric interface was used. The membranes were previously immersed in deionized water and the thickness was measured afterwards using a micrometer, taking the average of ten measurements at different parts of the surface. Then, the membranes were placed between two gold electrodes in a liquid parallel plate cell coupled to the spectrometer and deionized water was incorporated to ensure a fully hydrated state of the samples below 100 ${ }^{\circ} \mathrm{C}$ and an equilibrium with its vapor above $100{ }^{\circ} \mathrm{C}$. The temperature was controlled by nitrogen jet (QUATRO from Novocontrol) with a temperature error $\sim 0.1 \mathrm{~K}$ during every single sweep in frequency.

From the frequency dependence of the complex impedance $Z^{*}(\omega)=Z^{\prime}(\omega)+\mathrm{j} Z^{\prime \prime}(\omega)$, the real part of the conductivity is given as 


$$
\sigma^{\prime}(\omega)=\frac{Z^{\prime}(\omega) L}{\left[\left(Z^{\prime}(\omega)\right)^{2}+\left(Z^{\prime \prime}(\omega)\right)^{2}\right] S}=\frac{L}{R_{0} S}
$$

where $L$ and $S$ are the thickness and area of the sample in contact with the electrodes $\left(S=1.571 \mathrm{~cm}^{2}\right)$, respectively.

\section{Results and discussion}

\subsection{Scanning electron microscopy (SEM) analysis}

Fig. 1 shows SEM micrographs of the $\mathrm{SPEEK}_{70}-\mathrm{PVB}_{30}$ nanofiber mat with an electrospinning time of 12 hours; a predominant orientation of the fibers is observed (Fig. 1a). The nanofibers show no significant defects in their structure; therefore, it is possible to infer that our electrospinning process, under the set conditions and parameters, produces suitable nanofiber mats. The nanofiber mats had fiber diameters in the range of 300 to $1500 \mathrm{~nm}$ (Fig. 1b).

The surface and the cross-section of the final SPEEK-PVBPVA composite membrane are shown in Fig. 1c. From the micrographs, it is possible to observe that the nanofibers are properly embedded in the $\mathrm{SPEEK}_{65}-\mathrm{PVA}_{35}$ aqueous polymer matrix, mostly in the center of the membrane (1c-d). Furthermore, a compact membrane surface with minimal defects was observed, and no voids or pores with exposed fiber were observed (Fig. 1e).

The above observations confirmed that with our preparation method, it is possible to obtain membranes with sandwich structures with adequate penetration and impregnation of SPEEK-PVA polymer solution into the SPEEK-PVB nanofiber mat.

\subsection{Water uptake, swelling, ion exchange capacity and sulfonation degree}

The main goal of a proton exchange membrane, particularly those made of SPEEK, is the conductivity or transport of protons $\left(\mathrm{H}^{+}\right)$using the sulfonic acid groups $\left(-\mathrm{SO}_{3} \mathrm{H}\right)$ anchored to the polymer structure and the water retained in the membrane channels when hydrated. Therefore, it is important to promote
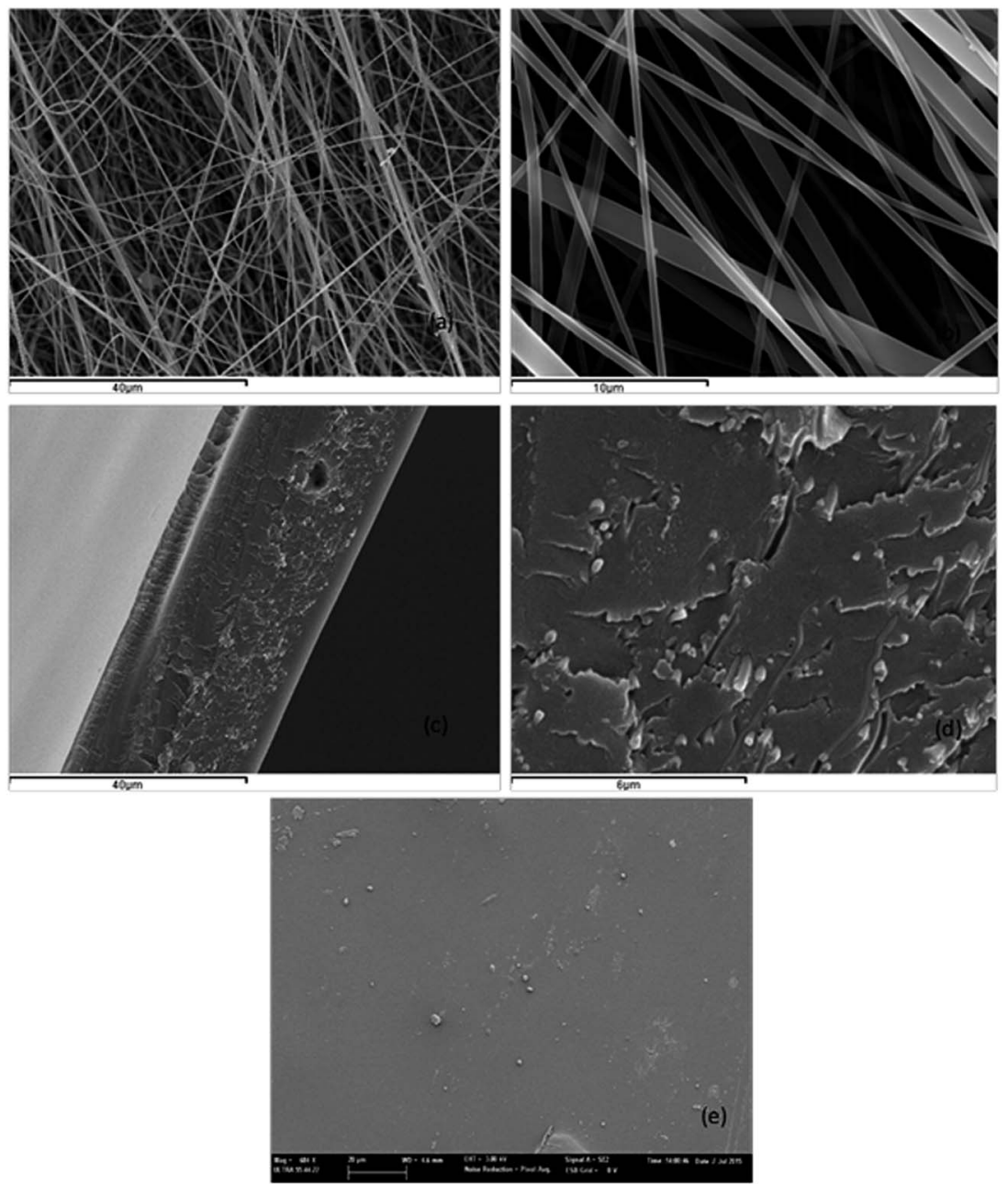

Fig. 1 SEM micrographs of the electrospun fiber mat prepared with $20 \mathrm{wt} \% \mathrm{SPEEK}_{70}-\mathrm{PVB}_{30}$ in DMAc for the sample with $12 \mathrm{~h}$ of electrospinning time. (a) Magnified $\times 1500$; (b) magnified $\times 5000$. SEM micrographs of the cross-linked SPEEK-PVB-PVA composite membrane using a SPEEK $_{70}-\mathrm{PVB}_{30}$ fiber mat with $12 \mathrm{~h}$ of electrospinning time. (c) Cross-section magnified $\times 1500$; (d) transversal section magnified $\times 10000$; (e) surface view magnified $\times 684$. 
proper PEEK sulfonation. The proton conductivity is related to the ion exchange capacity (IEC) of the material, which is a property that measures the density of sulfonic acid groups present in the polymeric chain of SPEEK. The presence of a high amount of acid groups in the material modifies its chemistry, increasing its hydrophilicity and allowing greater absorption of water in the ionic channels in the membrane; this facilitates the formation of hydrogen bonds between protons and water molecules. However, an excess of water in the material causes swelling and deformation of the membranes, which modifies their mechanical properties and decreases their conductivity; also, the material is more prone to dissolve in polar solvents such as methanol, ethanol or hot water..$^{28,31}$

Table 2 shows the values obtained for water uptake, swelling, ion exchange capacity and sulfonation degree for all composite membranes, pristine SPEEK and SPEEK-PVB nanofiber mats. It is observed that the pristine SPEEK polymer obtained after $12 \mathrm{~h}$ of sulfonation has an IEC of 2.35 meq $\mathrm{g}^{-1}$, which represents a sulfonation degree of $83 \%$, a high value when compared with commercial products ranging from 1.75 to $2.05 \mathrm{meq}^{-1}$. However, the IEC value of the SPEEK-PVB nanofibers decreases drastically to 0.60 meq $^{-1}(\mathrm{SD}=18 \%)$ when electrospun; this may be due to the presence of PVB in the crosslinking treatment applied to the fiber mats. When SPEEK-PVB is embedded with the SPEEK-PVA solution (SPEEK-PVB-PVA composite membranes), the IEC value increases to 1.58 to $1.71 \mathrm{meq}^{-1}$ (SD $=52$ to $57 \%$ ). We believe that SPEEK-PVA is responsible for the increase in IEC as a consequence of its higher sulfonation degree, influenced by the PVA OH- groups in the SPEEK chain. Previous studies carried out by our group have shown that the IEC of SPEEK-PVA membranes is around $0.22 \mathrm{meq} \mathrm{g}^{-1} \cdot{ }^{24-26} \mathrm{~A}$ slight downward trend is clearly observed in Table 2 in the value of IEC as the membrane thickness increases. The final membrane thickness is influenced by the thickness of the fiber mat obtained by varying the electrospinning time. In M-02, the thickness of the fibers was $9 \mu \mathrm{m}$, resulting in lower proportions of SPEEK-PVB with respect to the proportion of SPEEK-PVA polymer in the membrane; therefore, the IEC value will be slightly larger compared to that of M-14, with a fiber thickness of $140 \mu \mathrm{m}$, which has a higher proportion of SPEEK-PVB in the membrane and would result in a decreased IEC value for this membrane. For water uptake and swelling, the data do not show a meaningful trend.

\subsection{Mechanical properties}

Microtensile tests were carried out for the $12 \mathrm{~h}$ SPEEK-PVB nanofiber mats, SPEEK-PVB-PVA composite membranes and SPEEK-PVA pure membrane. These studies were performed with the purpose of evaluating the mechanical behavior and seeing the effect of the incorporation of the nanofibers in composite membranes. The measurements were performed in triplicate, and the average results with standard deviation were plotted. After obtaining the tensile stress vs. strain curves (Fig. 2a), mechanical parameters such as Young's modulus, the maximum tensile strength, the maximum strain and the tenacity were obtained and are shown in Table 3.

From the data in Table 3, it can be clearly seen that there are two limits: the maximum tensile strength in the SPEEK-PVB nanofiber sample (6.2 MPa) and the maximum tensile strength in the SPEEK-PVA sample (66.9 MPa). The results for all the samples of SPEEK-PVB-PVA composite membranes are within these limit values, and we can see an increase in the tensile strength as the membrane thickness is increased (with consequent thickening of the fiber mat through increasing electrospinning time). This trend is best seen in Fig. $2 \mathrm{~b}$. This means that the amount of SPEEK-PVB fibers in the composite membranes seems to have very little influence on their tensile strength. However, the incorporation of the fiber promotes increased stretch (high elasticity) before rupture, especially for fibers of longer electrospinning time (10 to $12 \mathrm{~h}$ ), compared with SPEEK-PVA pure membrane, which breaks abruptly (Fig. 2a). We can observe that the M-08 and M-14 membranes do not follow the same upward trend as the other membranes. We theorize that this is due to structural defects obtained during the preparation of the membranes and to water effects (the water uptake percentage and the degree of swelling that these membranes acquired).

\subsection{Electrochemical impedance spectroscopy (EIS)}

Impedance spectroscopy measurements were carried out for all membranes at different temperatures to obtain the conductivity

Table 2 Water uptake and swelling (in plane and through thickness), ion exchange capacity (IEC) and sulfonation degree (SD) values for pristine SPEEK, 12 h SPEEK-PVB nanofiber mat and the SPEEK-PVB-PVA composite membranes

\begin{tabular}{|c|c|c|c|c|c|c|}
\hline Pristine SPEEK & - & - & - & - & $2.35 \pm 0.00$ & $83 \pm 1$ \\
\hline M-02 & 112 & $238 \pm 7$ & $87 \pm 8$ & $34 \pm 2$ & $1.71 \pm 0.00$ & $57 \pm 0$ \\
\hline M-04 & 116 & $116 \pm 6$ & $49 \pm 8$ & $15 \pm 1$ & $1.72 \pm 0.00$ & $57 \pm 0$ \\
\hline M-06 & 124 & $158 \pm 3$ & $69 \pm 0$ & $78 \pm 3$ & $1.68 \pm 0.00$ & $56 \pm 0$ \\
\hline M-12 & 156 & $141 \pm 7$ & $47 \pm 0$ & $48 \pm 6$ & $1.60 \pm 0.00$ & $53 \pm 0$ \\
\hline M-14 & 168 & $161 \pm 11$ & $42 \pm 8$ & $45 \pm 2$ & $1.58 \pm 0.00$ & $52 \pm 0$ \\
\hline
\end{tabular}



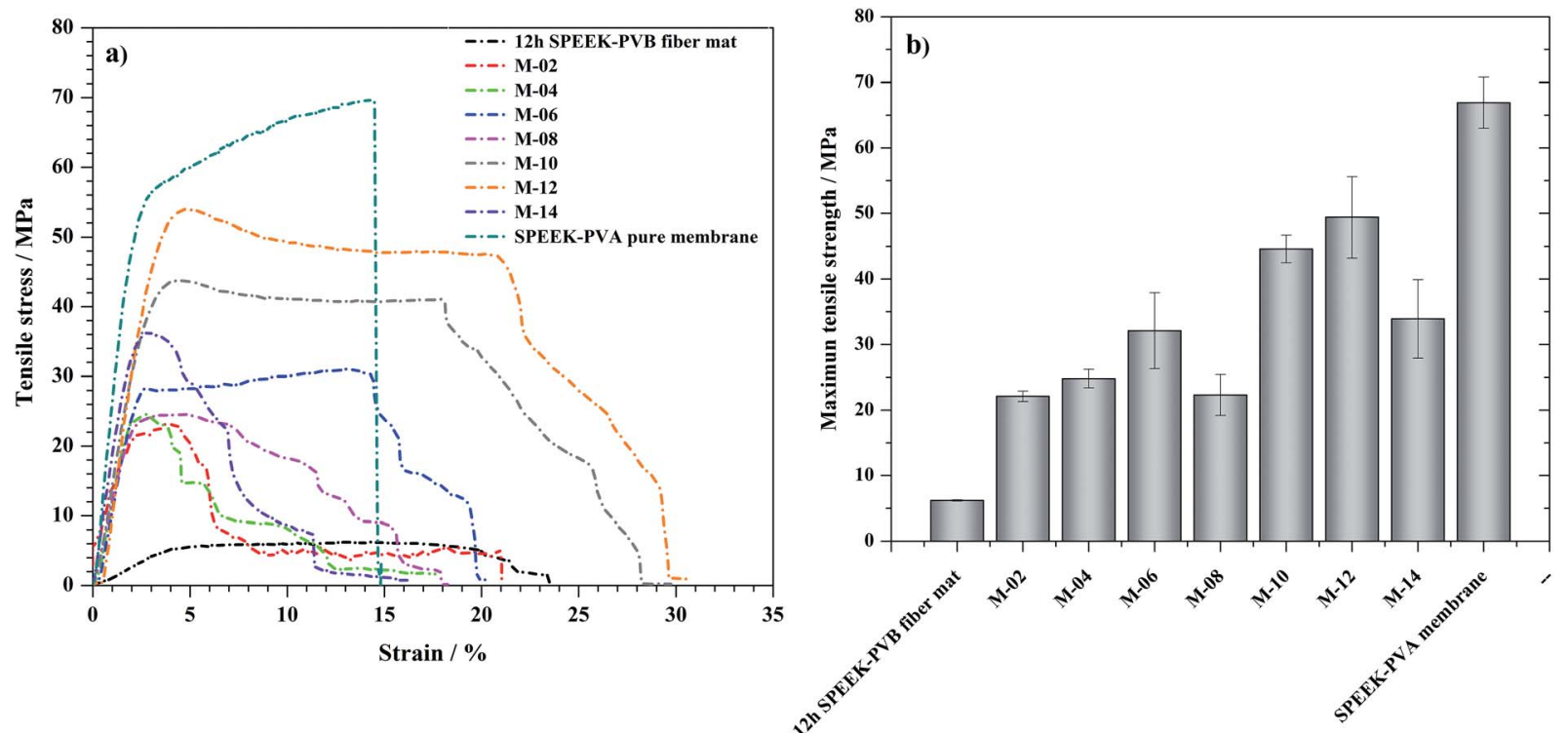

Fig. 2 (a) Tensile stress vs. strain curves obtained from tensile microtests for cross-linked $12 \mathrm{~h} \mathrm{SPEEK} \mathrm{SO}_{70}-\mathrm{PVB} 30$, the SPEEK-PVB-PVA composite membranes and pure SPEEK ${ }_{65}-P^{-} A_{35}$ membrane. (b) Maximum tensile strength for cross-linked 12 h SPEEK $K_{70}-P V B_{30}$, the SPEEK-PVB-PVA composite membranes and pure SPEEK $65-\mathrm{PVA}_{35}$ membrane.

Table 3 Young's modulus, maximum tensile strength, maximum strain and tenacity results from tensile microtests for cross-linked $12 \mathrm{~h}$

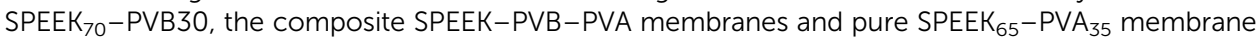

\begin{tabular}{|c|c|c|c|c|c|}
\hline Sample & $\begin{array}{l}\text { Membrane thickness } \\
(\mu \mathrm{m})\end{array}$ & $\begin{array}{l}\text { Young's } \\
\text { modulus } E(\mathrm{GPa})\end{array}$ & $\begin{array}{l}\text { Maximum tensile } \\
\text { strength } \sigma_{\max }(\mathrm{MPa})\end{array}$ & $\begin{array}{l}\text { Maximum strain } \\
\varepsilon_{\max }(\mathrm{mm})\end{array}$ & $\begin{array}{l}\text { Tenacity } \\
\left(\mathrm{MJ} \mathrm{m}^{-3}\right)\end{array}$ \\
\hline $12 \mathrm{~h}$ SPEEK-PVB fiber mat & 170 & $0.1 \pm 0.0$ & $6.2 \pm 0.1$ & $0.2 \pm 0.0$ & $1.0 \pm 0.1$ \\
\hline M-04 & 116 & $1.2 \pm 0.1$ & $24.8 \pm 1.4$ & $0.2 \pm 0.0$ & $1.8 \pm 0.3$ \\
\hline M-06 & 124 & $1.4 \pm 0.1$ & $32.1 \pm 5.8$ & $0.2 \pm 0.0$ & $3.5 \pm 1.6$ \\
\hline M-08 & 134 & $1.1 \pm 0.2$ & $22.3 \pm 3.1$ & $0.2 \pm 0.0$ & $1.5 \pm 0.1$ \\
\hline $\mathrm{M}-14$ & 168 & $1.7 \pm 0.1$ & $33.9 \pm 6.0$ & $0.1 \pm 0.0$ & $1.5 \pm 0.8$ \\
\hline SPEEK-PVA membrane & 110 & $2.7 \pm 0.5$ & $66.9 \pm 3.9$ & $0.2 \pm 0.1$ & $10.2 \pm 2.4$ \\
\hline
\end{tabular}

and the diffusion coefficient of the protons. From the complex dielectric measurements, the conductivity of the membranes was obtained by analyzing the data in terms of their dielectric permittivity $\varepsilon^{*}=\varepsilon^{\prime}-\mathrm{j} \varepsilon^{\prime \prime}$, where $\varepsilon^{\prime}$ and $\varepsilon^{\prime \prime}$ represent the real and imaginary parts of the permittivity and $\mathrm{j}$ represents the imaginary unity $\left(\mathrm{j}^{2}=-1\right)$. From the imaginary part, we can obtain the conductivity $\left(\sigma_{\mathrm{dc}}\right)$ when the Maxwell-Wagner-Sillar ${ }^{\mathbf{4 5 - 4 8}}$ (MWS) effects due to the bulk conductivity dominate as for a pure ohmic conduction, with $\varepsilon^{\prime \prime}=\sigma_{\mathrm{dc}} /\left(\varepsilon_{0} \omega\right)$, where $\varepsilon_{0}$ represents the permittivity of vacuum and $\omega$ represents the angular frequency of the applied electric field. This can be seen by the fact that the plot of the double logarithm plot of the dielectric loss versus frequency exhibits a slope of -1 ; this behavior is observed for our nanocomposite membranes for all thicknesses of SPEEKPVB nanofiber and all temperatures studied. Following this procedure, the conductivities of the composite membranes and the pure SPEEK-PVA membrane from $20^{\circ} \mathrm{C}$ to $140{ }^{\circ} \mathrm{C}$ have been obtained.
Fig. 3 shows the double logarithmic plots of the imaginary permittivity $\varepsilon$ " versus the frequency for the M-04 sample at all temperatures. The M-04 membrane was chosen from among all membranes because it can be a typical membrane for fuel cell applications, considering that it has a total thickness of $116 \mu \mathrm{m}$ composed of a nanofiber phase with a thickness of $15 \mu \mathrm{m}$ and a bulk phase approximately $101 \mu \mathrm{m}$ in thickness. From Fig. 3, we can see that the behavior of the SPEEK-PVB/SPEEK-PVA samples is linear in the region of high frequency, with a slope independent of the amount of nanofiber loading. The slope of the straight line is practically -1 for all the temperatures studied, with a correlation coefficient of 0.999 . This is the typical contribution to the dielectric loss from electrical conduction, which means that the behavior of the membranes for this interval of frequencies is that of a pure conductor. ${ }^{49}$ From the intercepts of the straight line observed at the high frequency region, shown in Fig. 3, we can obtain the values of the DC conductivity for the nanocomposites for each 


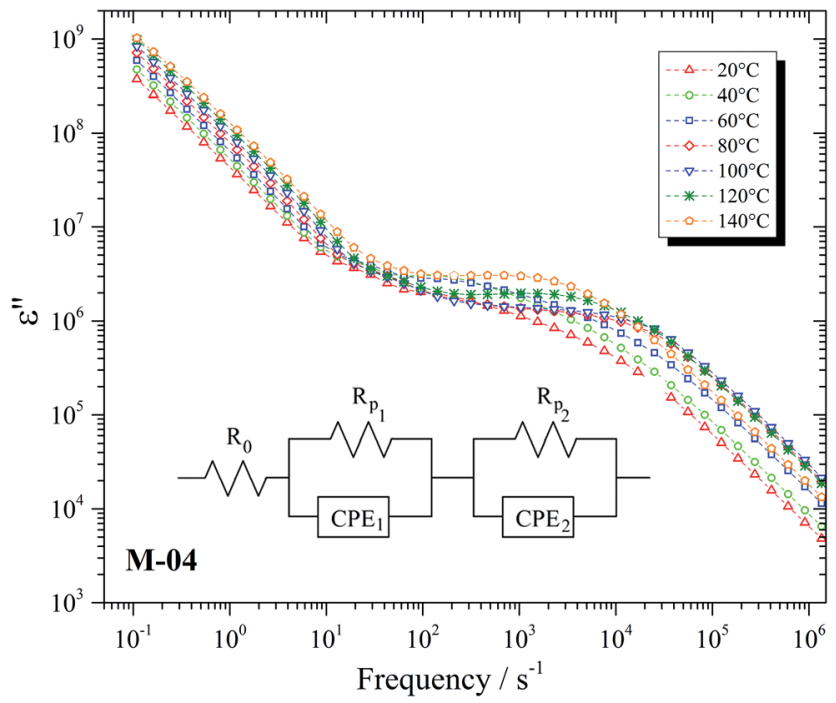

Fig. 3 Double logarithmic plot of the imaginary permittivity $\varepsilon^{\prime \prime}$ versus the frequency for the M-04 sample in the range of temperatures compressed between 80 and $140{ }^{\circ} \mathrm{C}$. The inset shows the equivalent electric circuits used to fit the experimental results obtained from impedance measurements of the SPEEK-PVB-PVA composite membranes.

temperature. For the rest of the membranes, similar behavior is observed, as shown in the ESI (Fig. S9-S15†). The values obtained for all the membranes are given in Table 4 .

To probe whether the conductivity obtained is the true conductivity of the composites, we have represented the Bode ${ }^{50}$ plot, shown in Fig. 4, where the real part of the conductivity, $\sigma^{\prime}$, and the phase angle $\left(^{\circ}\right.$ ) are represented as a function of the frequency for the M-12 sample. We can see on this figure that the real part of the conductivity, $\sigma^{\prime}$, reaches a constant value (plateau), and the phase angle $\left(^{\circ}\right)$ reaches a maximum close to zero in the high frequency region. Similar plots were found for the other samples (Fig. S1-S8 in the ESI $\dagger$ ).

In order to obtain exact values of $\sigma_{\mathrm{dc}}$, the impedance data in terms of conductivity were fitted by a Nyquist plot using the equivalent circuit shown in the inset of Fig. 3. In the equivalent circuit, the bulk resistance of the membrane, represented by $R_{0}$, is associated in series with a circuit composed of a resistance $R_{\mathrm{p}}$ (representing a polarization electrode resistance) in parallel with a constant phase element (CPE) of admittance $Y^{*}=$ $Y_{0}(\mathrm{j} \omega \tau)^{n}$, where $\mathrm{j}$ is the imaginary unit $\left(\mathrm{j}^{2}=-1\right), n$ is the exponent independent of frequency lying in the range $0<n<1, \omega$ $(=2 \pi f)$ is the angular frequency and $C$ is a CPE-parameter which represents the differential capacitance of the interface when $n=$ 1 , a resistor when $n=0$ and a inductor in the case of $n=-1$; however, when $n<1, C$ cannot represent the capacitance because its units are not simply Farads. ${ }^{51,52}$ This CPE accounts for the interfacial phenomena in the membrane-electrode interface. In this region, the Nyquist ${ }^{53}$ diagrams, $-Z^{\prime \prime}$ (imag.) vs. $Z^{\prime}$ (real), are semicircles intersecting the abscissa axis in the high frequency region at $Z^{\prime}=R_{0}$; this value permits us to obtain the DC conductivity. Semicircle-like waves are observed experimentally as a result of polarization processes and other possible phenomena taking place at the membrane electrode interface. In the cases where the systems combine polarization processes with a resistance independent of the frequency or ohmic resistance, $R_{0}$, the equivalent electrical circuit can be given by a series of $R_{\mathrm{p} i}$-CPE parallel circuits in series with $R_{0}$; such a case is represented in the inset of Fig. 3, where the complex impedance of the system is given by

$$
Z^{*}(\omega)=R_{0}+\sum_{i=1}^{2} \frac{R_{\mathrm{p} i}}{1+R_{\mathrm{p} i} Y_{0, i}\left(\omega \tau_{i}\right)^{n_{i}} \mathrm{j}^{n_{i}}}
$$

where the sum is extensive until $i=2$, corresponding to the best interpretation observed from the experimental results simulated by means of the electric circuit shown in the inset of Fig. 4.

A close inspection of Fig. 4 shows that the values of the real part of the conductivity reach a plateau when the phase angle tends to zero. In our samples, we can observe two plateaus: one situated in the region of high frequencies associated with the protonic conductivity in the bulk SPEEK-PVA pure membrane, identical to the bulk conductivity $\sigma_{\mathrm{dc}}$, reflecting long-range proton transport, and the other in the region of low frequencies that can be associated to the proton conductivity trough of the SPEEK-PVB nanofibers and also to the electrode polarization via the formation of electrochemical double layers and polymer relaxation. ${ }^{54-57}$ Between the regions of high and low frequency, there is a decrease in the conductivity that can be explained as a Debye relaxation due to the macroscopic polarization of the ionic charges as a consequence of the applied electric field. This relaxation is characterized by a relaxation time which is dependent on the temperature, the chemical structure of the membrane and its thickness. ${ }^{58-60}$ The value of the conductivity obtained in the region of high frequencies where the phase angle reaches zero, as previously stated, represents the proton conductivity of the membrane. In Table 4, we can see the values obtained for each of the composite membranes and for the pure SPEEK-PVA membrane for comparison.

In the inset of Fig. 4, we plotted the Nyquist diagram for the same temperatures represented in the Bode diagram of conductivities. In this figure, the real and imaginary components of the complex impedance are plotted for the entire range of frequencies. We can observe for all the composite membranes and for all temperatures two semicircles, intersecting the abscissa axis in the high frequency region at $Z^{\prime}=R_{0}$ (i.e. the membrane resistance). Semicircle-like waves are observed as a result of polarization processes, the two possible relaxation processes associated with the bulk and nanofiber components, and other phenomena taking place in the system composed of the SPEEK/PVB nanofiber-SPEEK/PVA bulk-electrode interface.

To appreciate the existence of the two relaxation processes associated with the SPEEK-PVB nanofiber and the SPEEK-PVA bulk observed from the Bode plots, we have also analyzed the experimental results from the Nyquist plot shown in the inset of Fig. 3, corresponding to the fit $-Z^{\prime \prime} v s$. $Z^{\prime}$. The solid line that appears in the inset corresponds to the best fit of $-\mathrm{Z}^{\prime \prime} v s . \mathrm{Z}^{\prime}$ to the experimental values previously represented by symbols at 
Table 4 Values of the diffusion coefficient, activation energy and conductivity obtained by Bode and Nyquist diagrams and by $\varepsilon^{\prime \prime}$ vs. frequency plots for the SPEEK-PVB-PVA composite membranes and the pure SPEEK ${ }_{65}-\mathrm{PVA}_{35}$ membrane. $\sigma_{\mathrm{DC}}$ is the direct current conductivity

\begin{tabular}{|c|c|c|c|c|c|c|}
\hline \multicolumn{7}{|c|}{ Sample: M-02; $L: 112 \mu \mathrm{m}$} \\
\hline 80 & 15.5 & $15.1 \pm 0.4$ & $11.4 \pm 2.1$ & 2.8 & $22.4 \pm 2.9$ & 6.67 \\
\hline 100 & 17.8 & $17.7 \pm 0.4$ & $14.5 \pm 2.8$ & 3.5 & & 8.48 \\
\hline 120 & 17.6 & $17.5 \pm 0.3$ & $16.1 \pm 3.1$ & 3.6 & & 9.42 \\
\hline 140 & 16.2 & $16.4 \pm 0.1$ & $19.9 \pm 2.4$ & 3.5 & & 11.64 \\
\hline
\end{tabular}

Sample: M-04; L: $116 \mu \mathrm{m}$

$\begin{array}{ll}80 & 19.4 \\ 100 & 21.7 \\ 120 & 18.5 \\ 140 & 12.7\end{array}$

Sample: M-06; $L: 124 \mu \mathrm{m}$

$\begin{array}{lr}80 & 9.4 \\ 100 & 14.6 \\ 120 & 17.9 \\ 140 & 15.2\end{array}$

Sample: M-08; $L: 134 \mu \mathrm{m}$

$\begin{array}{ll}80 & 11.2 \\ 100 & 14.2 \\ 120 & 14.5 \\ 140 & 12.9\end{array}$

Sample: $M-10 ; L: 150 \mu \mathrm{m}$

$\begin{array}{ll}80 & 16.5 \\ 100 & 19.5 \\ 120 & 20.8 \\ 140 & 18.5\end{array}$

Sample: M-12; L: $156 \mu \mathrm{m}$

$\begin{array}{ll}80 & 29.2 \\ 100 & 38.2 \\ 120 & 38.2 \\ 140 & 35.5\end{array}$

Sample: M-14; $L: 168 \mu \mathrm{m}$

$\begin{array}{ll}80 & 24.3 \\ 100 & 30.4 \\ 120 & 31.5 \\ 140 & 28.6\end{array}$

Sample: pure SPEEK-PVA membrane; $L: 134 \mu \mathrm{m}$

\begin{tabular}{|c|c|c|c|c|c|c|}
\hline 80 & 2.8 & $2.4 \pm 0.1$ & $2.7 \pm 0.4$ & 1.3 & $33.4 \pm 2.2$ & 4.66 \\
\hline 140 & - & - & - & - & & - \\
\hline
\end{tabular}

each temperature in the Nyquist plot inside the Bode diagram. In Table 4, we gather all the membrane conductivities obtained by Bode and Nyquist plots at several temperatures.

The conductivity values change very little when we compare the method used to estimate them at each temperature, and they increase by about 100 to 1000 times when the amount of nanofiber increases. From these results, we can observe that the proton conduction mechanism is more efficient through the surface of the SPEEK-PVB nanofibers than through the matrix of SPEEK-PVA; similar results have been observed in other nanocomposites. ${ }^{\mathbf{6 1 , 6 2}}$ On the other hand, it is possible to observe a critical thickness as a function of the electrospinning time (M-12 with 12 hours of electrospinning time of SPEEKPVB) where the protonic conductivity is the highest, as shown in Fig. 5a.

A similar comparison of the protonic conductivity values as a function of the temperature analyzed by EIS is shown in Fig. 6, where the SPEEK-PVB-PVA M-12 composite membrane showed the highest values at 120 to $140{ }^{\circ} \mathrm{C}$. The conductivity of the composite membrane $\mathrm{M}-14$ at $140{ }^{\circ} \mathrm{C}$ is about $0.03 \mathrm{~S}$ 


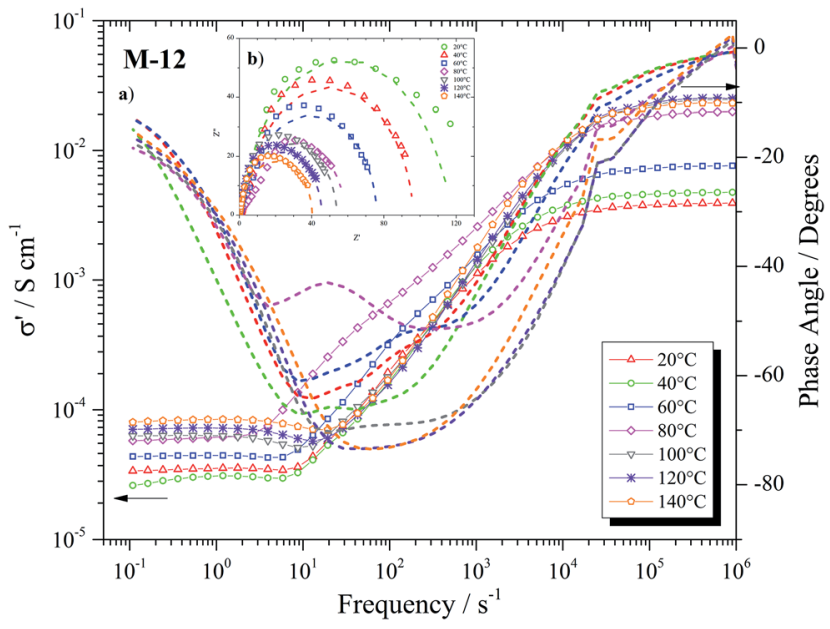

Fig. 4 Bode diagram for the M-12 SPEEK-PVB-PVA composite membrane at several temperatures: $20,40,60,80,100,120$ and $140{ }^{\circ} \mathrm{C}$. The inset shows the Nyquist plot for the same membrane and the same interval of temperatures.

$\mathrm{cm}^{-1}$, quite similar to Nafion membranes under DMFC operation at $70{ }^{\circ} \mathrm{C}^{63}$ This result is noteworthy because it shows that these new composite membranes can be applied in this temperature range while maintaining good conductivity compared with Nafion membranes, which are susceptible to degradation. ${ }^{8,9}$

Proton transport in acidic membranes is a complex process involving diverse steps: the dissociation of the proton from the fixed sulfonic acidic groups and its transfer through the SPEEKPVB nanofibers and the SPEEK-PVA matrix. Taking into account that the measured conductivity is due to the contribution of all the charge carriers and knowing that these are disseminated both through the nanofiber phase (SPEEK-PVB) and through the matrix phase (SPEEK-PVA bulk), we can observe, in a first approximation, that the total resistance to the proton transport can be given as:

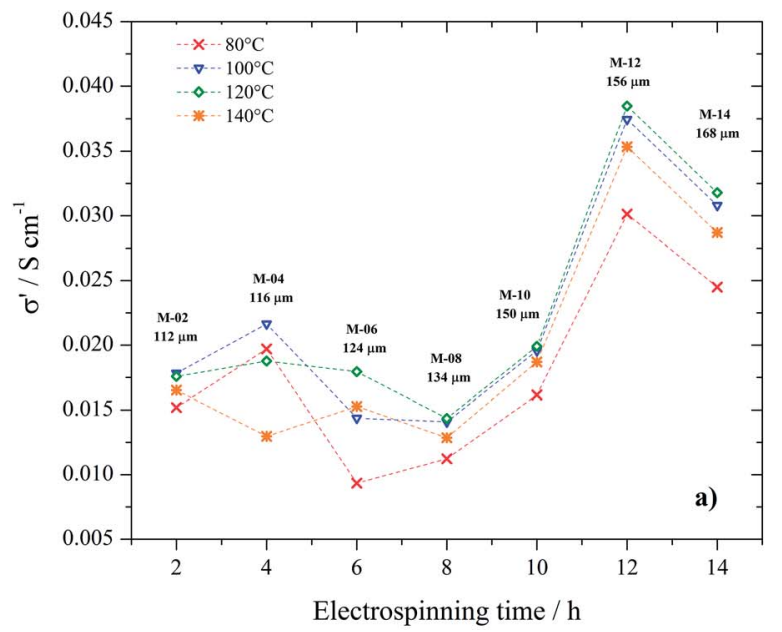

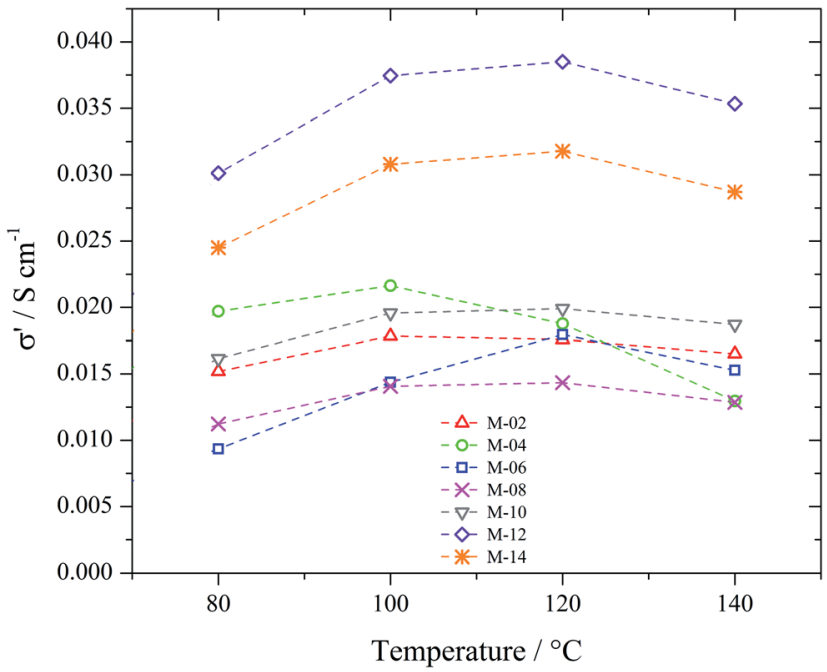

Fig. 6 Conductivity comparison for all the SPEEK-PVB-PVA composite membranes obtained as a function of the temperature, analyzed by EIS.

$$
\frac{1}{R_{\text {membrane }}}=\frac{1}{R_{\text {nanofiber }}}+\frac{1}{R_{\text {bulk }}}
$$

Taking into account eqn (6), we have:

$$
\left(\frac{\sigma S}{L}\right)_{\text {membrane }}=\left(\frac{\sigma S}{L}\right)_{\text {nanofiber }}+\left(\frac{\sigma S}{L}\right)_{\text {bulk }}
$$

Assuming that the area is the same for the phases, bulk and nanofiber, we have in first approximation that:

$$
\left(\frac{\sigma}{L}\right)_{\text {membrane }}=\left(\frac{\sigma}{L}\right)_{\text {nanofiber }}+\left(\frac{\sigma}{L}\right)_{\text {bulk }}
$$

We determined $L_{\text {nanofiber }}$ and $L_{\text {membrane }}$ experimentally; consequently, we can give an estimate of the thickness of the

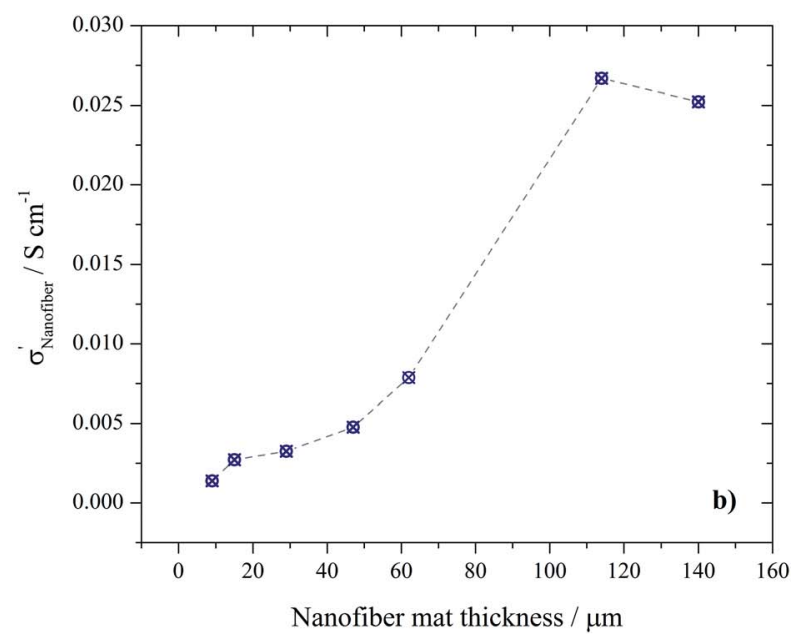

Fig. 5 (a) Conductivity comparison for all the SPEEK-PVB-PVA composite membranes obtained as a function of the electrospinning time and temperature. (b) Conductivity comparison for all the SPEEK-PVB nanofiber mats as a function of the electrospinning time. 
matrix phase. Furthermore, we have determined the conductivity of the composite membrane and of the membrane without nanofiber. Thus, we can approximately estimate the contribution of the nanofibers to the conductivity of the composite membrane.

For example, it can be seen that for the M-08 membrane, at a temperature of $100{ }^{\circ} \mathrm{C}$, with a nanofiber thickness of $134 \mu \mathrm{m}$ and a thickness of the SPEEK-PVA bulk phase identical to the corresponding pure SPEEK-PVA membrane, it is readily apparent that the nanofiber has 10 times higher conductivity than the matrix phase. To do this, the conductivity value of the pure PVA-SPEEK membrane $\left(0.5 \times 10^{-3} \mathrm{~S} \mathrm{~cm}^{-1}\right)$ given in Table 5 is considered. Similarly, for the M-12 membrane, the conductivity value calculated for the nanofiber $(114 \mu \mathrm{m})$ is 2.67 $\times 10^{-2} \mathrm{~S} \mathrm{~cm}^{-1}$. This value is very similar to the value of $2.61 \times$ $10^{-2} \mathrm{~S} \mathrm{~cm}^{-1}$ obtained in a previous study ${ }^{24}$ and indicates that our nanofibers have a conductivity about 50 times higher than the SPEEK-PVA phase. The results for all the composite membranes are shown in Table 5 and Fig. $6 \mathrm{~b}$, where comparisons of the conductivity for all the composite membranes as a function of the nanofiber mat thickness are given.

Therefore, as an evident conclusion and fully justifying some approximations, we can say that conductivity occurs more easily through the nanofiber than through the SPEEK-PVA phase. These results are in agreement with the literature, ${ }^{62,64}$ where it is found that the proton conductivity of SPEEK nanofiber mat is nearly five times as high as that of the SPEEK composite membrane. Our result is also consistent with the work of Hongwei et al., ${ }^{62}$ where two possible pathways are presented: (1) the long-range proton conductivity pathways are formed inside of the nanofibers, ${ }^{65}$ and (2) the long-range proton conductivity pathways are formed on the surfaces of the nanofibers. ${ }^{64}$ Conductivity may be improved through the bulk due to an induced orientation of the ionic channels along the nanofiber axis; otherwise, conductivity may be encouraged on the nanofiber surface through the strong interface formed between water molecules and external sulfonic groups.

The measure of the conductivity carried out in our work is transversal. The in-plane method only gives the conductivity value in the longitudinal direction (OX) or (OY); however, for

Table 5 Values of the estimated contribution of SPEEK-PVB nanofiber mats and SPEEK-PVA bulk to the conductivity of the SPEEKPVB-PVA membranes

\begin{tabular}{llll}
\hline $\begin{array}{l}\text { Composite } \\
\text { membrane }\end{array}$ & $\begin{array}{l}\sigma_{\text {membrane }} \times 10^{2} \\
\left(\mathrm{~S} \mathrm{~cm}^{-1}\right)\end{array}$ & $\begin{array}{l}\sigma_{\text {nanofiber }} \times 10^{2} \\
\left(\mathrm{~S} \mathrm{~cm}^{-1}\right)\end{array}$ & $\begin{array}{l}\sigma_{\text {nanofiber }} / \\
\sigma_{\text {bulk }}\end{array}$ \\
\hline M-02 & 1.77 & 0.14 & 2.8 \\
M-04 & 2.15 & 0.27 & 5.4 \\
M-06 & 1.44 & 0.33 & 6.6 \\
M-08 & 1.41 & 0.48 & 9.6 \\
M-10 & 1.96 & 0.79 & 15.8 \\
M-12 & 3.71 & 2.67 & 53.4 \\
M-14 & 3.09 & 2.52 & 50.4 \\
SPEEK-PVA & 0.05 & & \\
pure membrane & & & \\
(bulk) & & &
\end{tabular}

applications in fuel cells, we need the transversal value (i.e. through the sample). To acquire this, we must sandwich a sample between two electrodes (gold electrodes in our study). The nanofibers were collected using a rotating drum collector where the flow rate conditions of SPEEK-PVB solution are injected in the direction of the cathode collector where practically all the nanofibers are aligned. Since the conductivity measurement is transversal, we can suppose that the protons move transversally to the sample (nanofibers). For this reason, we are in agreement with Hongwei's explanation: number 2 and number 1 would be unfavorable to proton transfer between nanofibers.

In Fig. 7, we plot the Arrhenius plot of the conductivity of the nanocomposite membranes in the temperature range from $20{ }^{\circ} \mathrm{C}$ to $140{ }^{\circ} \mathrm{C}$ except for the pure SPEEK-PVA membrane, where the temperature range was from $20^{\circ} \mathrm{C}$ to $100{ }^{\circ} \mathrm{C}$. From these results, we clearly observe two regions: a region of decrease in conductivity above $100{ }^{\circ} \mathrm{C}$, with a bigger decrease in the case of pure SPEEK-PVA membrane, and another region at low temperature where Arrhenius behavior is observed for the conductivity. The difference between these two regions can be explained by taking into account that in the nanofiber phase (SPEEK-PVB), the charge transport takes place via a hopping mechanism between sulfonic groups in a frozen disorder structure. ${ }^{\mathbf{6 6}, 67}$ However, in the phase matrix composed of the polymer SPEEK-PVA, the diffusion of protons takes place both via a hopping mechanism and via $\mathrm{H}_{3} \mathrm{O}^{+}$decrease by the effect of an increase in temperature due to the evaporation of water molecules from the polymeric matrix. Therefore, it is expected that higher values of activation energy will be associated to a higher amount of matrix phase, and smaller values should be expected with a higher amount of nanofiber phase. The activation energy is calculated in the interval where the Arrhenius plot presents a linear behavior. The obtained results are also given in Table 4, being in all cases smaller than the value obtained for the pure SPEEK-PVA membrane.

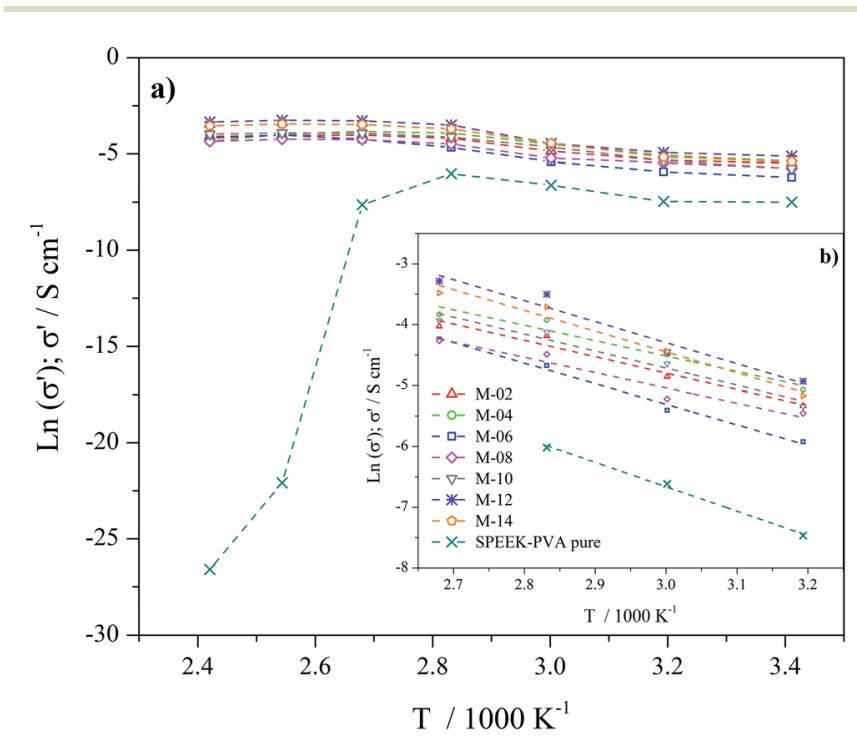

Fig. 7 Arrhenius plot for the SPEEK-PVB-PVA composite membranes and pure $\mathrm{SPEEK}_{65}-\mathrm{PVA}_{35}$ membrane. 
In binary systems, all the available ions participate in the ionic transport, since most of them may be interacting to form pairs or clusters; thus, it is very difficult to obtain the true contribution of each ion to the ionic transport. The conductivity is obtained for the complete system, and it represents the sum of the total contributions of the mobile charges, i.e., $\sigma=$ $\sigma_{+}+\sigma_{-}$. In studies to measure the diffusivity of ILs in polymerized ionic liquids (PILs) using the method of pulsed field gradient (PFG) NMR measurements, it has been observed that the conductivity of the PIL is greater than that of its molecular counterpart. ${ }^{66}$ This indicates that the cation mobility is very slow to provide a significant contribution to the true conductivity of the samples, and this should be dominated by the contributions of the anions. Thus, although all the available charges participate in the ionic transport, it can be assumed that the highest plausible contribution to the true conductivity, $\sigma=\sigma_{\mathrm{dc}}$, for all the samples, is the mobility of the anions. Therefore, the diffusion coefficient can be calculated from the conductivity measurements, assuming that it is only associated with the contributions of the anions. From the experimental results of the conductivity associated with the protons (cations) and the ionic exchange capacity of the nanocomposite membranes, the diffusion coefficient has been estimated. ${ }^{54,68}$

$$
D_{+}=\frac{R T N_{\mathrm{A}}}{F^{2}} \frac{\sigma_{\mathrm{dc}}}{c_{\text {ion }}}
$$

where $\sigma_{\mathrm{dc}}$ represents the DC-conductivity gathered in Table 4, determined from the Bode diagram, $R$ is the gas constant, $\mathrm{F}$ is the Faraday constant, $N_{\mathrm{A}}$ is the Avogadro number, $T$ is the absolute temperature and $c_{\text {ion }}$ is the concentration of protons in the membrane that are considered equal to the ionic exchange capacity.

In Table 4, we show the values obtained for the proton diffusion coefficient in each of the composite membranes in the temperature range of 80 to $140{ }^{\circ} \mathrm{C}$. Table 4 shows that the diffusivity of protons for each of the membranes increases as a function of the ionic concentration (protons) available in the membrane, varying with the relation $\frac{\sigma_{\mathrm{DC}}}{c_{\mathrm{ion}}}$ and with the temperature. The same increment is observed as the membrane thickness increases because there is more protonic exchange polymeric material inside the membrane, as seen in Tables 1 and 2

\section{Conclusions}

SPEEK-PVB nanofiber mats were obtained by an electrospinning method using an optimum $20 \mathrm{wt} \% \mathrm{SPEEK}_{70}-\mathrm{PVB}_{30} /$ DMAc polymer solution. Different thicknesses of nanofiber mats were obtained as a function of the electrospinning time ( 2 to 14 hours) with the purpose of studying the effect of the thickness in the proton conductivity. The nanofiber mats were cross-linked at $180{ }^{\circ} \mathrm{C}$ for $2 \mathrm{~h}$ and then were embedded by infiltration in a $12 \mathrm{wt} \% \mathrm{SPEEK}_{65}-\mathrm{PVA}_{35} / \mathrm{H}_{2} \mathrm{O}$ polymer solution to obtain SPEEK-PVB-PVA composite membranes identified as $M-x$, where $x$ is the number of hours of electrospinning time used to obtain the SPEEK-PVB nanofiber mats later embedded in the SPEEK-PVA polymer solution. SEM micrographs revealed that the SPEEK-PVB nanofibers were obtained without defects during the electrospinning method under the conditions applied, and the optimum polymer solutions were used. On the other hand, the cross-section SEM micrographs obtained for the M-12 membrane showed good embedding of the SPEEK-PVB nanofiber in the SPEEK-PVA matrix with our method of fabrication. Mechanical tests showed that the nanofiber incorporation has a positive effect on the reinforcement of the composite membranes when compared with a pure SPEEK-PVA membrane. In other words, the composite membranes have more elasticity before rupture when the nanofiber mat thickness increases. Impedance spectroscopy studies allowed us to obtain the proton conductivity for all the composite membranes by three different methods: (1) Bode diagram, (2) Nyquist plot and (3) the double logarithm plot of the dielectric loss versus frequency, all of which produced very similar results. This study reveals an optimal thickness of nanofiber mat as function of the electrospinning time $(12 \mathrm{~h})$ in the composite membrane (M-12), which had a conductivity of $3.71 \times 10^{-2} \mathrm{~S} \mathrm{~cm}^{-1}$. Furthermore, it was possible to obtain the conductivity of the SPEEK-PVB nanofiber phase as an estimation of the nanofiber conductivity, which can be up to 50 times higher than the conductivity of the SPEEK-PVA phase (bulk phase). These results indicate that the proton conduction takes place through the nanofibers and allows us to establish that the more favorable pathway of proton conduction is through the surface of the nanofiber due to the incorporation of a SPEEK-PVB phase. While the maximum conductivity for the obtained composite membrane is low compared to commercial Nafion membranes at temperatures below $90{ }^{\circ} \mathrm{C}$, the importance of this study is that the new membranes can function in a temperature range of 100 to $140{ }^{\circ} \mathrm{C}$, maintaining good proton conductivity and stability without being susceptible to degradation at those temperatures. This advantage makes the SPEEK-PVB-PVA composite membranes a suitable candidate for applications in fuel cells at intermediate temperature, specifically in the range from 100 to $140{ }^{\circ} \mathrm{C}$.

\section{Acknowledgements}

This research has been supported by the ENE/2011-24761 project, granted by the Ministerio de Economía y Competitividad (MINECO), Spain, and grants from CONACYTSENER-SUSTENTABILIDAD ENERGÉTICA 2014-02-245920 through Centro de Investigación y de Estudios Avanzados del Instituto Politécnico Nacional (CINVESTAV), México. José Luis Reyes-Rodriguez thanks CONACYT Program for a fellowship at the Universidad Politécnica de Valencia (UPV).

\section{References}

1 S. Zhong, X. Cui, H. Cai, T. Fu, C. Zhao and H. Na, J. Power Sources, 2007, 164, 65-72. 
2 L. Li, J. Zhang and Y. Wang, J. Membr. Sci., 2003, 226, 159167.

3 S. Smitha, S. Sridhar and A. A. Khan, J. Membr. Sci., 2005, 259, 10.

4 S. Tan and D. Bélanger, J. Phys. Chem., 2005, 109, 23480.

5 A. Iulianelli and A. Basile, Int. J. Hydrogen Energy, 2012, 37, 15241-15255.

6 S. Bose, T. Kuila, T. Nguyen, T. X. H. Nguyen, N. H. Kim, K. Lau and J. H. Lee, Prog. Polym. Sci., 2011, 36, 813-843.

7 A. Eguizábal, J. Lemus, V. Roda, M. Urbiztondo, F. Barreras and M. P. Pina, Int. J. Hydrogen Energy, 2012, 37, 7221-7234.

8 Q. Li, R. He, J. O. Jensen and N. J. Bjerrum, Chem. Mater., 2003, 15, 4896-4915.

9 Y. Shao, G. Yin, Z. Wang and Y. Gao, J. Power Sources, 2007, 167, 235-242.

10 S. J. Paddison, Annu. Rev. Mater. Res., 2003, 33, 289-319.

11 S. M. Haile, D. A. Boysen, C. R. I. Chilson and R. B. Merle, Nature, 2001, 410, 910-913.

12 G. Liu, H. Zhang, Y. Zhai, Y. Zhang, D. Xu and Z. Shao, Electrochem. Commun., 2007, 9, 135-141.

13 O. Savadogo, J. Power Sources, 2004, 127, 135-161.

14 J. L. Zhang, Z. Xie, J. J. Zhang, Y. H. Tanga, C. J. Song, T. Navessin, et al., J. Power Sources, 2006, 160, 872-891.

15 W. H. J. Hogarth, J. C. D. da Costa and G. D. Lu, J. Power Sources, 2005, 142, 223-237.

16 Q. Li, R. He, J. O. Jensen and N. J. Bjerrum, Fuel Cells, 2004, 4, 147-159.

17 C. Yang, P. Costamagna, S. Srinivasan, J. Benziger and A. B. Bocarsly, J. Power Sources, 2001, 103, 1-9.

18 M. E. Schuster and W. H. Meyer, Annu. Rev. Mater. Res., 2003, 33, 233-261.

19 J. S. Wainright, J. T. Wang, D. Weng, R. F. Savinell and M. Litt, J. Electrochem. Soc., 1995, 142, L121-L123.

20 S. Wasmus, A. Valeriu, G. D. Mateescu, D. A. Tryk and R. F. Savinell, Solid State Ionics, 1995, 80, 87.

21 R. F. Savinell and M. H. Litt, US Pat. 5,525,436, 1996.

22 J. T. Wang, R. F. Savinell, J. S. Wainright, M. H. Litt and H. Yu, Electrochim. Acta, 1996, 41, 193.

23 Q. F. Li, J. O. Jensen, R. F. Savinell and N. J. Bjerrum, Prog. Polym. Sci., 2009, 34, 449-477.

24 S. Mollá and V. Compañ, J. Membr. Sci., 2015, 492, 123-136.

25 S. Mollá and V. Compañ, J. Power Sources, 2011, 196, 26992708.

26 S. Mollá and V. Compañ, Int. J. Hydrogen Energy, 2014, 39, 5121-5136.

27 N. Nishad Fathima, R. Aravindhan, D. Lawrence, U. Yugandhar, T. S. R. Moorthy and B. Unni Nair, J. Sci. Ind. Res., 2007, 66, 209-219.

28 S. D. Mikhailenko, K. Wang, S. Kaliaguine, P. Xing, G. P. Robertson and M. D. Guiver, J. Membr. Sci., 2004, 233, 93-99.

29 R. Y. M. Huang, P. Shao, C. M. Burns and X. Feng, J. Appl. Polym. Sci., 2001, 82, 2651-2660.

30 P. Knauth, H. Hou, E. Bloch, E. Sgreccia and M. L. Di Vona, J. Anal. Appl. Pyrolysis, 2011, 92, 361-365.

31 D. Daoust, J. Devaux and P. Godard, Polym. Int., 2001, 50, 917-924.
32 V. R. Hande, S. K. Rath, S. Rao and M. Patri, J. Membr. Sci., 2011, 372, 40-48.

33 S. Sambandam and V. Ramani, J. Power Sources, 2007, 170, 259-267.

34 J. G. Liu, T. S. Zhao, Z. X. Liang and R. Chen, J. Power Sources, 2006, 153, 61-67.

35 B. J. Ballengee and P. N. Pintauro, Macromolecules, 2011, 44, 7307-7314.

36 B. Wu, J. Pan, L. Ge, L. Wu, H. Wang and T. Xu, Sci. Rep., 2014, 4, 1-7.

37 T. Tamura, R. Takemori and H. Kawakami, J. Power Sources, 2012, 217, 135-141.

38 D. M. Yu, S. Yoon, T.-H. Kim, J. Y. Lee, J. Lee and Y. T. Hong, J. Membr. Sci., 2013, 446, 212-219.

39 C. Lee, S. M. Jo, J. Choi, K.-Y. Baek, Y. B. Truong, I. L. Kyratzis and Y.-G. Shul, J. Mater. Sci., 2013, 48, 3665-3671.

40 S. H. Wang and H.-L. Lin, J. Power Sources, 2014, 257, 254263.

41 H. L. Lin and S. H. Wang, J. Membr. Sci., 2014, 452, 253-262. 42 I. Shabani, M. M. Hasani-Sadrabadi, V. Haddadi-Asl and M. Soleimani, J. Membr. Sci., 2011, 368, 233-240.

43 Z. Hongwei, Y. Fei and Z. Danying, J. Appl. Polym. Sci., 2013, 130, 4581-4586.

44 A. Baji, Y. W. Mai, S. C. Wong, M. Abtahi and P. Chen, Compos. Sci. Technol., 2010, 170, 703-718.

45 J. C. Maxwell. A treatise of Electricity \& Magnetism, Dover, NY, 1954.

46 K. W. Wagner, Arch. Elektrotech., 1914, 2, 371.

47 K. W. Wagner, Arch. Elektrotech., 1914, 3, 67.

48 R. W. Sillars, Proc. Inst. Electr. Eng., 1937, 80, 378.

49 A. Munar, A. Andrio and R. Iserte, J. Non-Cryst. Solids, 2011, 357, 3064-3069.

50 H. W. Bode, Netwok Analysis and Feedback Amplifier Design, ed. Van Nostrand, Princeton, NJ, 1945.

51 B. Hirschorn, M. E. Orazem, B. Tribollet, V. Vivier, I. Frateur and M. Musiani, Electrochim. Acta, 2010, 55, 6218.

52 J. R. MacDonald, Impedance Spectroscopy, Emphasizing solid materials and systems, Wiley-Interscience, 1987.

53 H. Nyquist, Phys. Rev., 1928, 32, 110.

54 T. S. Sorensen and V. Compañ, J. Chem. Soc., Faraday Trans., 1995, 91, 4235-4250.

55 M. Drüschler, B. Hubber, S. Passerini and B. Roling, J. Phys. Chem. C, 2011, 115, 6802-6808.

56 A. Serguei, M. Tress, J. R. Sangoro and F. Kremer, Phys. Rev. B: Condens. Matter Mater. Phys., 2009, 80, 184301-184305.

57 F. Kremer and A. Schoenhals. Broadban Dielectric Spectroscopy, Springer, Berlin, 2003.

58 J. Klein, S. Zhang, S. Dou, B. H. Jones, R. Colby and J. Runt, J. Chem. Phys., 2006, 124, 144903.

59 R. Coelho, Sur la relaxation d'une charge d'espace, Rev. Phys. Appl., 1983, 18, 137.

60 E. Barsoukov and J. R. MacDonald, Impedance Spectroscopy: Theory, Experiment and applications, Wiley-Interscience, Chchester, 2005, ch. 2, pp. 87-88.

61 Y. Zhao, Z. Jiang, D. Lin, A. Dong, Z. Li and H. Wu, J. Power Sources, 2011, 224, 28-36. 
62 Z. Hongwei, Y. Fei and Z. Danying, J. Appl. Polym. Sci., 2013, 130, 4581.

63 C. Prapainainar and S. M. Holmes. Sustainability in Energy and Buildings: Research Advances. Proton conductivity of Nafion® membrane in actual direct methanol fuel cell operation. Special Edition - Mediterranean Green Energy Forum, 2013 (MGEF-13), vol. 2, pp. 31-35: mgf13s-023.

64 X. Li, X. Hao, D. Xu, G. Zhang, S. Zhong, H. Na and D. Wang, J. Membr. Sci., 2006, 281, 1.
65 B. Dong, L. Gwee, D. Salas-de la Cruz, K. I. Winey and Y. A. Elabd, Nano Lett., 2010, 10, 3785.

66 N. K. Karan, D. K. Pradhan, R. Thomas, B. Natesan and R. S. Katiyar, Solid State Ionics, 2008, 179, 689-696.

67 E. Parcero, F. J. Fernández-Carretero, V. Compañ, R. Herrera, L. F. del Castillo and E. Riande, J. Electrochem. Soc., 2008, 155, F245-F252.

68 T. S. Sorensen, V. Compañ and R. Diaz-Calleja, J. Chem. Soc., Faraday Trans., 1996, 92, 1947. 